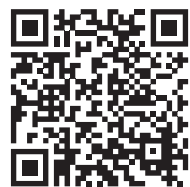

Octubre - Diciembre 2021 Vol. 1, núm. 1 / pp. 18-25

\section{El colgajo en isla submental: una alternativa en la reconstrucción orofacial. Descripción de la técnica y reporte de casos}

\author{
The submental island flap as an alternative in orofacial \\ reconstruction. Description of the technique and case report
}

Zoilo Núñez Gil*
Palabras clave: Cáncer oral, reconstrucción oral, colgajo submentoniano

Keywords:

Oral cancer, oral reconstruction, submental flap.

Citar como: Núñez GZ. El colgajo en isla submental: una alternativa en la reconstrucción orofacial. Descripción de la técnica y reporte de casos. Lat Am

J Oral Maxillofac Surg. 2021; 1 (1): 18-25. https://dx.doi. org/10.35366/101913

* Cirujano Bucal y Maxilofacial. Jefe del Servicio de Cirugía Maxilofacial de Instituto Nacional del Cáncer (INCART). Jefe del Servicio

de Cirugía Maxilofacial del Hospital Regiona

Universitario San Vicente de

Paul. República Dominicana.

Profesor de anatomía

y patología quirúrgica

maxilofacial, Universidad

Católica Nordestana (UCNE).

Recibido: $18 / 08 / 2021$

Aceptado: 28/08/2021

doi: $10.35366 / 101913$

\section{RESUMEN}

Introducción: El colgajo submentoniano proporciona una técnica alternativa en la reconstrucción orofacial especialmente en situaciones en las que no se dispone de servicios gratuitos de colgajo. Objetivo: El objetivo de este estudio es mostrar la técnica quirúrgica y los beneficios de este jirón en la reparación orofacial, en un hospital oncológico de tercer nivel. Material y métodos: Se realizó un estudio retrospectivo que incluyó 13 pacientes con cánceres orales, quienes se sometieron a reconstrucción con colgajo submentoniano entre 2017 y 2021 en el Servicio de Cirugía Maxilofacial del Instituto Nacional del Cáncer (INCART). Se describe la anatomía pertinente y el método quirúrgico. Se presentan tres casos ilustrativos. Resultados: Esta serie contó con 11 pacientes femeninos y dos masculinos con edades comprendidas entre los 24 y los 82 años. La ubicación de tumores primarios más común fue la lengua. De ellos, 11 se sometieron a una disección selectiva del cuello ipsilateral y un bilateral, después del levantamiento del colgajo. Se observó pérdida parcial del recorte en un caso. El seguimiento medio fue de 11 meses. Hubo una recurrencia regional, pero ninguna recidiva local. En el último seguimiento (mínimo seis meses), 10 afectados estaban vivos sin ninguna enfermedad, dos estaban vivos con la enfermedad y uno había fallecido. Conclusión: El colgajo submentoniano es una opción satisfactoria para la reconstrucción de la cavidad bucal. El colgajo en isla submental es una fuente confiable de piel, de excelente color, forma, y textura para la reparación orofacial y deja un sitio donante bien oculto. Se sugiere que este jirón es una valiosa adición al arsenal quirúrgico existente.

\section{ABSTRACT}

Introduction: The submental flap provides an alternative technique in orofacial reconstruction, especially in situations where free flap services are not available. Objective: The objective of this study is to show the surgical technique and the benefits of this flap in orofacial reconstruction in a tertiary cancer hospital. Material and methods: A retrospective study was carried out that included 13 patients with oral cancers, who underwent reconstruction with a submental flap between 2017 and 2021 at the Maxillofacial Surgery Service of the National Cancer Institute (INCART). Relevant anatomy and surgical technique are described, through three illustrative cases. Results: This series had 11 female and two male patients aged between 24 and 82 years. The most common primary tumor site was the tongue. Eleven of the patients underwent selective ipsilateral neck dissection and one bilateral, after flap lift. Partial loss of the flap was observed in one case. The mean follow-up was 11 months. There was a regional recurrence, but no local recurrence. At the last follow-up (minimum six months), 10 patients were alive without any disease, two were alive with the disease, and one had died. Conclusion: The submental flap is a successful option for oral cavity reconstruction. The submental island flap is a reliable source of skin, of excellent color, shape, and texture for orofacial reconstruction, and leaves a well-hidden donor site. This author believes that such flap is a valuable addition to the existing surgical arsenal.

\section{INTRODUCCIÓN}

El colgajo de isla submental es una técnica eficaz para la reconstrucción en el territorio maxilofacial. Entre sus características, es eficiente por ser versa- tilidad, de poco espesor, color, textura y mínima morbilidad en la zona donante. Su evolución dentro del campo quirúrgico maxilofacial ha evolucionado mucho; sin embargo, son muchas las controversias que aún se generan con su uso. ${ }^{1-3}$ 


\section{Material y métodos}

Se describen la anatomía y la técnica quirúrgica del colgajo submental. Se realizó un estudio retrospectivo de pacientes en quienes se realizaron recortes bajo el mentón para la reconstrucción orofacial, llevados a cabo en el Servicio de Cirugía Oral y Maxilofacial del Instituto Nacional del Cáncer (INCART) en el periodo de 2017 hasta 2021; se analizaron los resultados y se presentan tres casos. Todos los involucrados fueron operados por el mismo cirujano con la misma técnica.

\section{Anatomía y técnica quirúrgica}

La arteria submental surge de la arteria facial, profunda a la glándula submandibular. ${ }^{4,5}$ Viaja, en una curva suave, hacia adelante bajo el borde mandibular y medialmente sobre el músculo milohioideo, la arteria va profunda al vientre anterior del músculo digástrico en $70 \%$ de los casos y superficialmente en el $30 \%$ de ellos, ${ }^{6,7}$ emitiendo de dos a seis perforantes cutáneas que penetran primero el músculo digástrico y luego el músculo platisma suprayacente, antes de formar un plexo subdérmico que se anastomosa ampliamente con las ramas contralaterales. ${ }^{8}$

La citada arteria termina detrás de la sínfisis mandibular, justo lateralmente a la línea media, en el vientre anterior del músculo digástrico, desde donde envía ramas al labio inferior y la glándula sublingual. ${ }^{9}$ El colgajo es drenado por la vena del mismo nombre, que a su vez drena en la vena facial común en la superficie de la glándula submandibular. ${ }^{7}$

\section{Planificación del colgajo}

El colgajo se puede levantar con anestesia local o general. El paciente se coloca en decúbito supino con la cabeza y el cuello moderadamente extendido. La paleta cutánea llega a alcanzar hasta $10 \mathrm{~cm}$ por $16 \mathrm{~cm}$, el pedículo alcanza hasta $5 \mathrm{~cm}$ y se incluyen el músculo platisma, una parte del milohioideo, así como el músculo digástrico anterior. ${ }^{8}$ La arteria facial pasa por el borde mandibular justo por el ángulo anteroinferior del masetero (Figura 1A).
Si se va a realizar la disección de cuello, ésta comienza primero, teniendo extrema precaución para preservar los vasos del rostro. Luego, una vez completada tal intervención, comienza la extracción del colgajo. Este abordaje debe garantizar un procedimiento oncológicamente seguro. Al acercarse al triángulo submandibular, la arteria y la vena faciales se separan cuidadosamente de la glándula submandibular ligando las ramas que van a la glándula y preservando los vasos submentonianos. En caso de que sea necesaria una disección bilateral del cuello, el jirón ha de tomarse en el lado menos afectado del mismo, que debe completarse primero. ${ }^{10}$

El colgajo se planifica como se muestra (Figura 1B). En primer lugar, el límite superior del recorte se dibuja detrás del borde inferior mandibular, teniendo cuidado de no invadir demasiado hacia delante, lo que produciría una cicatriz visible. Esta incisión se podría extender posteriormente en el lado ipsilateral a fin de permitir un mayor corte del pedículo vascular si es necesario.

\section{Levantamiento del colgajo}

El primer paso cuando se levanta el colgajo es identificar y preservar la rama marginal mandibular del nervio facial justo debajo del platisma y que recubre la arteria facial. El pedículo del recorte se puede disecar, aunque en la mayoría de los colgajos este paso llega a considerarse innecesario, ya que un pedículo de amplia base podría ser suficiente para permitir la colocación del jirón sin tensión. Dicha arteria se dirige anteriormente $y$, a medida que desaparece detrás de la glándula submandibular, la retracción hacia abajo en la glándula revelará la arteria submental. La vena submental se llega a identificar ya que se encuentra en la superficie de la glándula que drena hacia la vena facial común.

Se realizan incisiones en los márgenes del colgajo y se levanta el recorte, comenzando en el lado contralateral, levantando y disecando todos los tejidos encima de los músculos milohioideo y digástrico contralateral, y dirigiéndose hacia el pedículo, que podría estar completamente esqueletizado o no (Figura 2A-B). Esto produce un colgajo grande de piel, con

Figura 1:

A) Anatomía de vasos submentales, señalado con flecha. B) Diseño de colgajo.
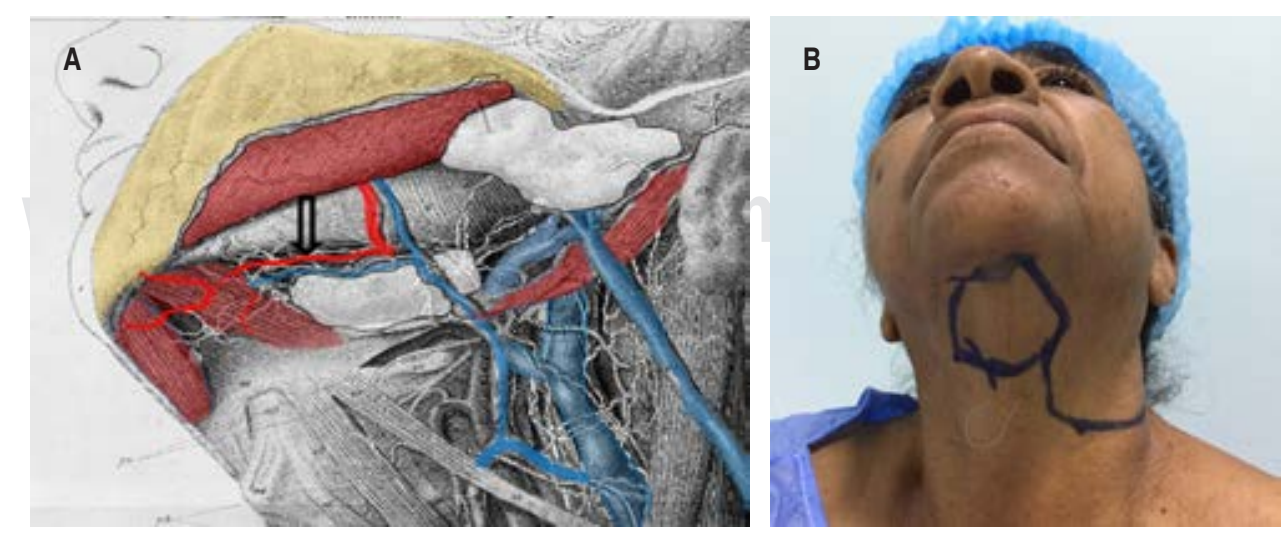

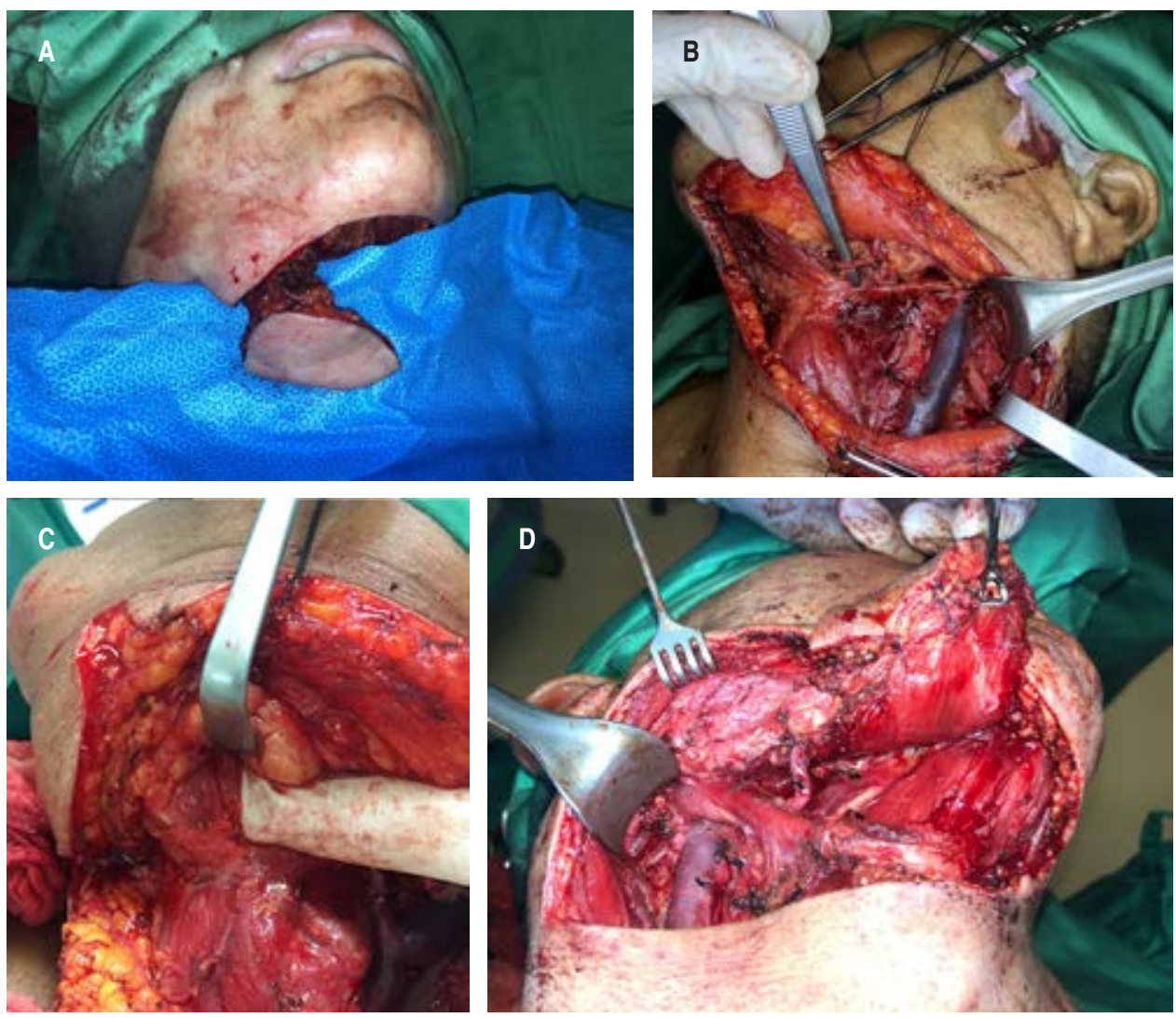

Figura 2:

A) Colgajo levantado sin esqueletizar la arteria submental. B) Fotografía de una disección de cuello donde se señala con la pinza dicha arteria esqueletizada, dirigiéndose hacia debajo del vientre anterior del músculo digástrico a través del cual atraviesan varias arterias perforantes cutáneas. C) Dedo introducido por debajo del músculo milohioideo para levantar el colgajo submental según la modificación de Patel y colegas en su parte inferior. $\boldsymbol{D}$ ) Colgajo levantado, fíjese en la sutura del músculo con la dermis para evitar el cizallamiento cutáneo.

un pedículo confiable y resistente que puede ser tunelizado a su sitio receptor.

Una modificación a la técnica es la propuesta por Patel y colaboradores, ${ }^{11}$ la cual es todavía mucho más segura, en ésta se levanta el colgajo junto con el músculo milohioideo, conociendo que la arteria submentoniana estaba profunda al vientre anterior del músculo digástrico (Figura 2C-D).

Importante es la sutura del músculo a la piel del colgajo a fin de evitar el cizallamiento de la piel, causa de la pérdida de la parte cutánea del recorte, pudiendo ocasionar fibrosis por la cicatrización de segunda intención. ${ }^{12}$

A menudo, el sitio donante se cierra directamente con o sin disección adicional, pero si se requiere movilización de la piel, debe hacerse sólo en el lado cervical para evitar la eversión del labio inferior. Si es necesaria esa movilización, la piel cervical ha de suturarse al hueso hioides buscando mantener el ángulo cervicomental. ${ }^{13}$

\section{Alargamiento del pedículo}

El método descrito anteriormente produce un pedículo largo, fiable, siendo posible aumentar la longitud del pedículo por corte adicional en una de tres maneras: ${ }^{7}$
1. Dividir los vasos faciales distales al origen de la arteria submental proporciona 1-2 $\mathrm{cm}$ adicionales de longitud en el pedículo. Sin embargo, el orden de cosas pronto se vuelve tenso y limita cualquier avance ulterior (Figura 3A).

2. La vena facial común o submental podría ser dividida y anastomosada, siguiendo el paso 1 , a una adecuada vena cerca del sitio de destino (Figura 3B).

3. Martin y colegas ${ }^{6}$ sugirieron que incluso más avance del pedículo llega a lograrse por la división de los vasos faciales proximales al origen de la arteria facial y elevar la totalidad del colgajo de manera que el flujo sanguíneo sea inverso, y en esta forma se puede llevar al tercio medio y superior de la cara (Figura 3C).

\section{Presentación de casos}

Caso 1: Defecto en lengua. Paciente femenino de 71 años de edad, presentando un carcinoma de células escamosas en el borde lateral de la lengua (T2 N0 M0). Ella se sometió a una disección supraomohioidea con glosectomía parcial y colgajo en isla submental para la reconstrucción. Este recorte ofreció una reparación que restauraba el volumen de la lengua mientras mantenía la misma libremente móvil, procurando 
facilitar el habla y la deglución, nótese en la imagen cómo hizo metaplasia el colgajo (Figura 4).

Caso 2: Defecto intraoral. Paciente femenina de 82 años de edad, con un carcinoma de células escamosas en el trígono retromolar y reborde alveolar inferior (T4 N0 M0). Ella se sometió a una amplia resección tumoral con mandibulectomía segmentaria y remodelación con colgajo en isla submental y placa puente de $2.7 \mathrm{~mm}$ de reconstrucción. Este colgajo ofreció una simple reparación de toda esa región y su porción alveolar, dando cobertura a la placa puente y a la región del trígono mandibular (Figura 5).

Caso 3: Defecto facial. Paciente femenina de 82 años de edad, con diagnóstico de carcinoma mucinoso submucosa en todo el carrillo derecho y con perforación cutánea en la región geniana. En el examen clínico, el tumor se palpaba muy próximo a la mucosa, extendiéndose de manera submucosa, sin linfoadenopatía. La lesión fue extirpada ampliamente en la región geniana (incluyendo la comisura labial, buscando márgenes
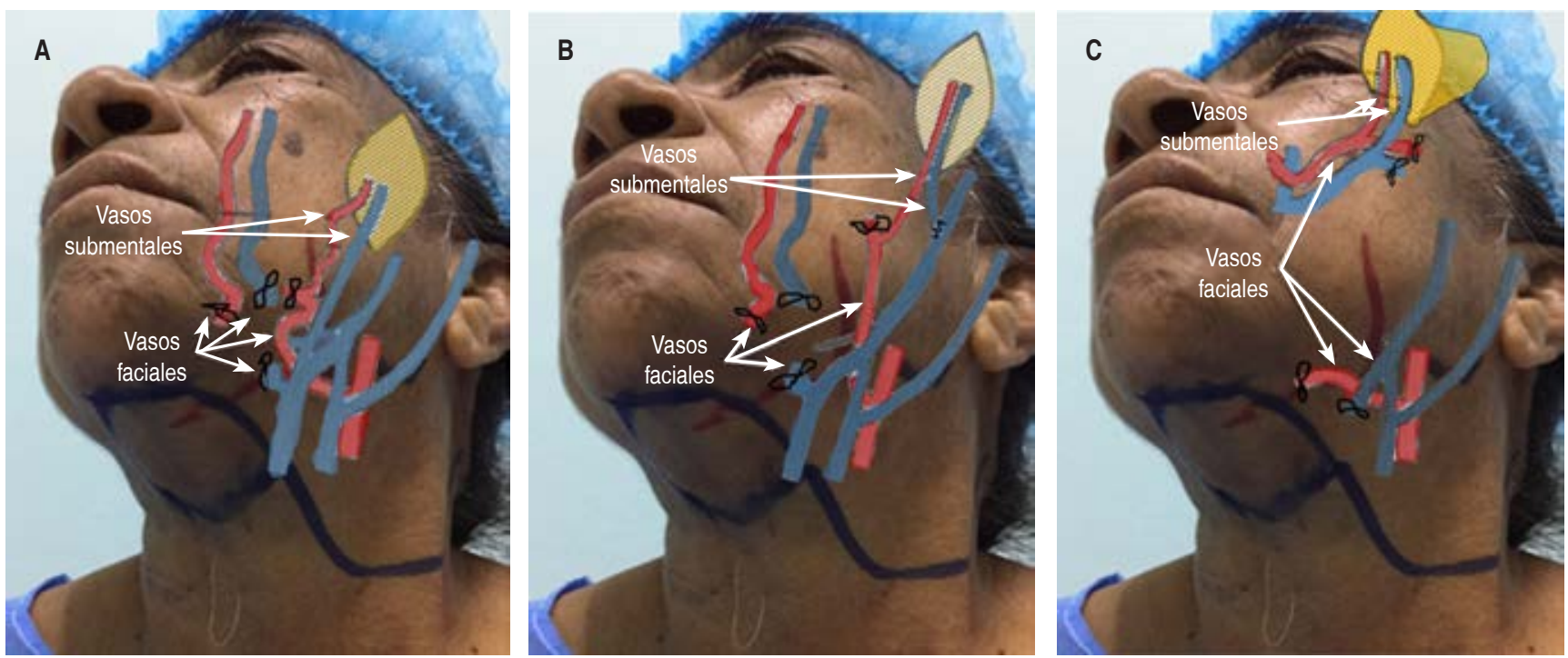

Figura 3: Maneras de alargar el pedículo. A) Dividiendo los vasos faciales distal al origen de la arteria submental. B) La vena facial común o submental puede ser dividida y anastomosada a una adecuada vena cerca del sitio de destino. C) División de los faciales vasos proximal al origen de la arteria facial y elevar la totalidad del colgajo de manera que el flujo sanguíneo sea inverso.
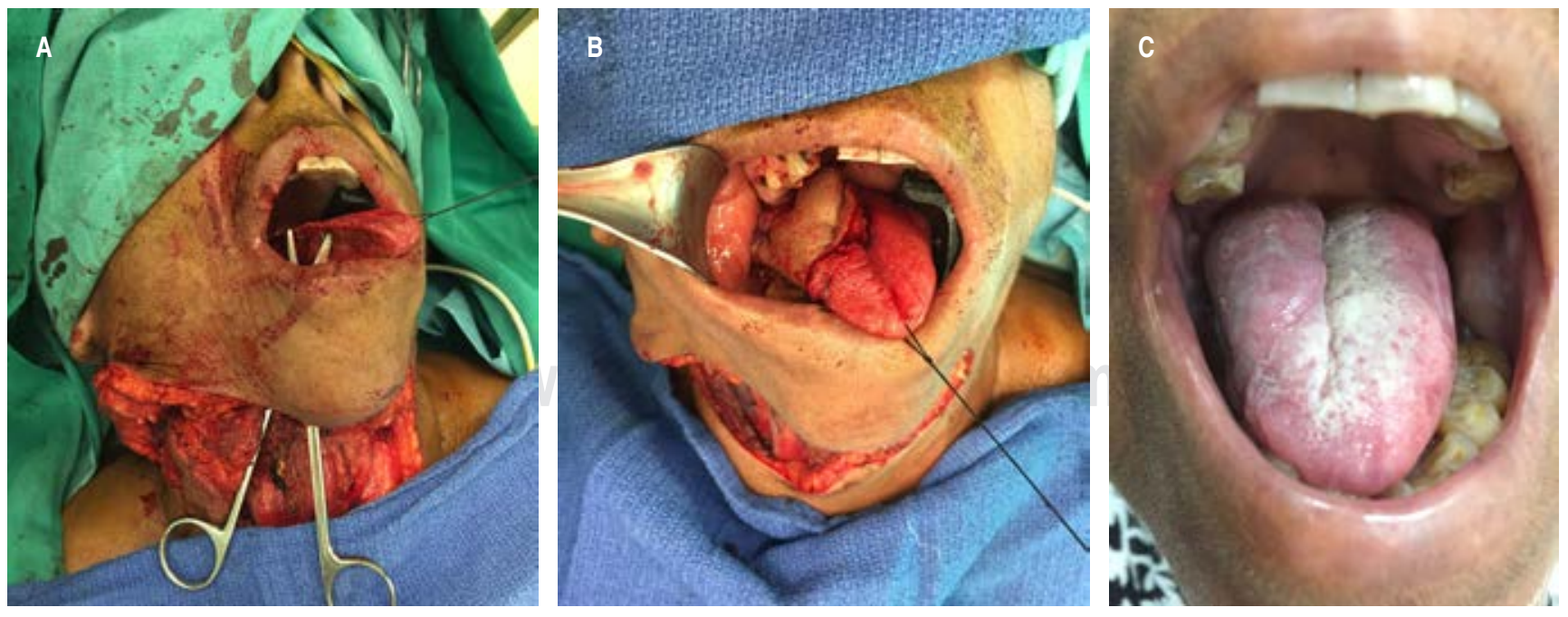

Figura 4: Caso 1. Defecto en lengua. 

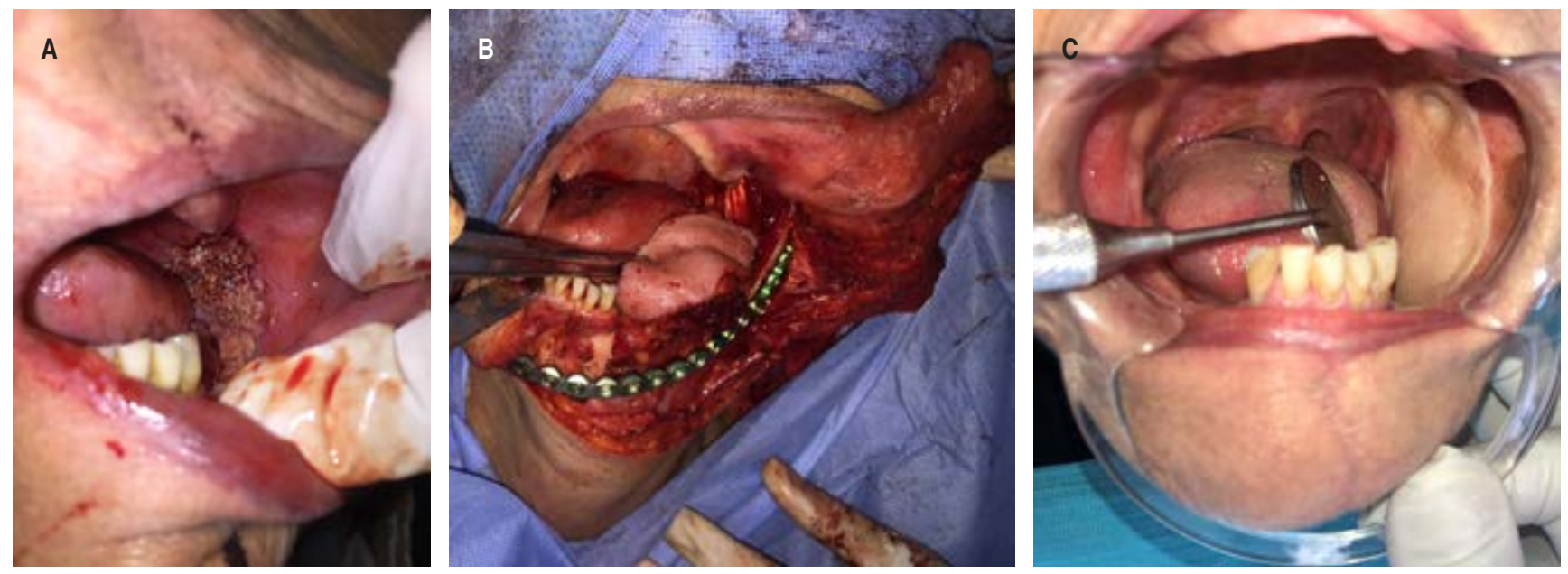

Figura 5: Caso 2. Defecto intraoral.
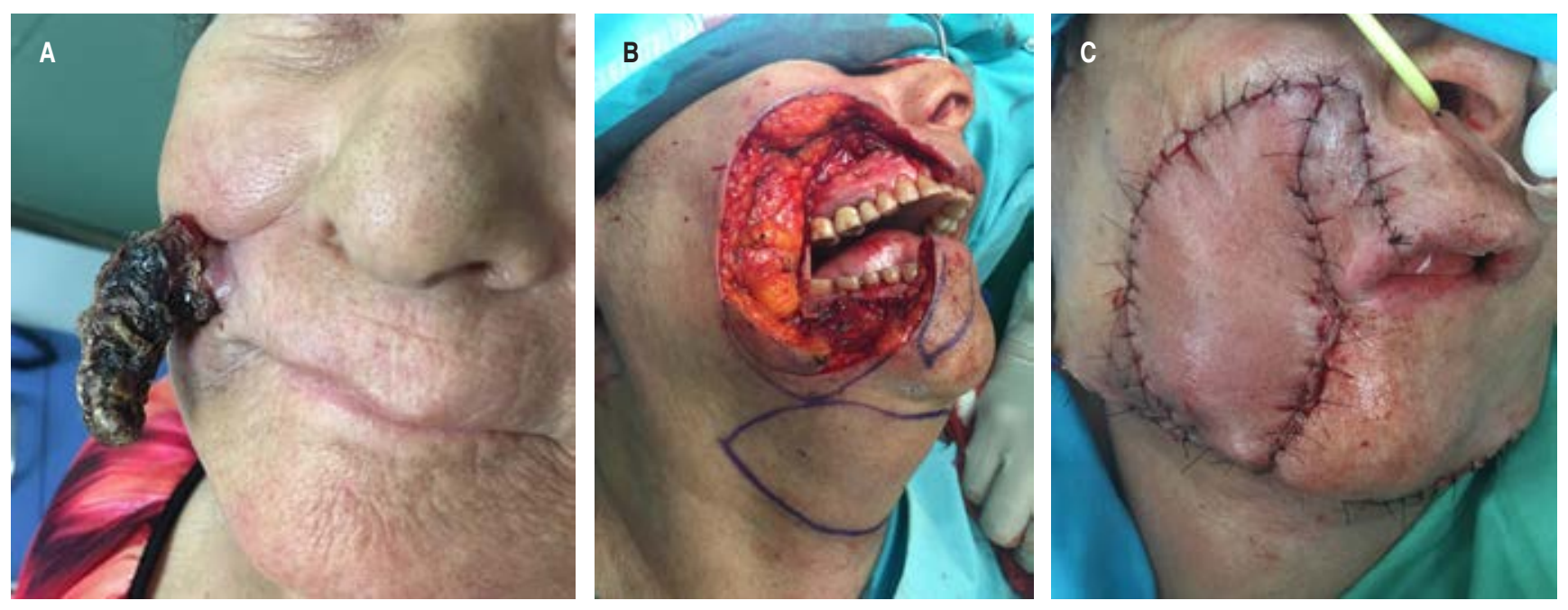

Figura 6: Caso 3. Defecto facial.

de seguridad) y el defecto fue reparado usando un colgajo en isla submental y un colgajo de rotación tipo Estlander para la reconstrucción de la comisura labial. Sin incidentes postoperatorios, fue dada de alta al hogar en el quinto día (Figura 6).

\section{Resultados}

Se realizó el colgajo de la isla submental según la modificación de Patel en 13 pacientes (10 mujeres y tres hombres) entre 2017 y 2021. La edad media de los pacientes fue de 70.6 años (rango 24 a 82 años); siendo los ancianos más adecuados para este recorte ya que tienen una abundancia de piel y tejido laxo bajo el mentón.
La duración media de la elevación e inserción del colgajo, sin disección pedicular adicional, fue de 40 minutos. La estancia postoperatoria media fue de 3.6 días (Tabla 1). Todos los sitios donantes cicatrizaron bien, sin movimientos restringidos del cuello.

La principal morbilidad asociada con este procedimiento es la parálisis marginal del nervio mandibular, no encontrada en esta serie. Los resultados fueron satisfactorios en 11 personas intervenidas, atendiendo a los criterios de cobertura del defecto, estética y funcionalidad.

Aunque es un colgajo pequeño, ha cubierto con éxito la placa de reconstrucción asegurada en casos de mandibulectomía segmentaria sin una sola extrusión interna. El recorte se 
utilizó con satisfacción en la remodelación, después de la resección intraoral compuesta de la mandíbula en dos pacientes.

En dicha serie hubo dos complicaciones (15.3\%), una congestión del colgajo por el pobre drenaje venoso, que se solucionó con masajes y tiempo; y una pérdida parcial de la piel del retazo por cizallamiento, al no suturar la piel al tejido subyacente del recorte.

Se realizaron 13 disecciones cervicales supraomohioideas y una de cuello bilateral. Los resultados histológicos de los cuellos fueron: N0 en ocho ocasiones (66.7\%), N1 en tres (25\%), y N2 en una ocasión (8.3\%). En ningún caso se detectó transferencia de enfermedad tumoral cervical al lecho receptor. Sólo se ha evidenciado recurrencia local de la enfermedad en un paciente y metástasis regional en otro.

En los pacientes masculinos, el pelo en el colgajo era escaso y producía una apariencia de «piel de gallina». En todos los casos, el sitio donante sanó bien, sin cicatrices hipertróficas y sin restricción al movimiento del cuello. En un evento se requirió la reducción de volumen del recorte, esto se realizó nueve meses después de la operación.

\section{Discusıón}

En los centros de gran volumen y bajos recursos, varios colgajos pediculados continúan desempeñando un papel crucial. ${ }^{13}$ Durante la última década, el recorte en isla submentoniano ha demostrado ser una opción reconstructiva fiable en la cirugía de cabeza y cuello, siendo un procedimiento sencillo y rápido de realizar. Proporciona un tejido relativamente delgado y bien vascularizado en una operación de un solo estadio y evita la necesidad de una segunda intervención para dividir el pedículo o la realización de técnicas microquirúrgicas sofisticadas. ${ }^{12}$ Aunque es un jirón pequeño, ha cubierto con éxito la placa de reconstrucción asegurada en eventos de mandibulectomía segmentaria. ${ }^{14}$

La ecografía Doppler color con localización de las arterias o venas faciales y perforantes cutáneas reduce drásticamente la tasa de fallos, ${ }^{11}$ aunque en esta serie no se utilizó.

Se debe considerar cuidadosamente el uso del colgajo para la reconstrucción después de la escisión de una neoplasia maligna intraoral. La principal preocupación es que los nódulos linfáticos potencialmente afectados podrían quedar en el recorte o su pedículo.

Sin embargo, es simple realizar una disección profiláctica de los nódulos linfáticos en el triángulo submental y triángulos submandibulares del cuello al levantar el colgajo. En la literatura, existe controversia acerca de la potencialidad de este recorte para transferir enfermedad metastásica cervical al lugar receptor, así como de la imposibilidad de llevar a cabo un riguroso corte cervical del nivel I. No obstante, el plano de división del retazo es subplatismal, que es el mismo en el que se lleva a cabo la disección cervical, por lo tanto, si se respetan los planos anatómicos, las probabilidades de diseminación del tumor pueden ser minimizadas. ${ }^{15}$

En un estudio donde se realizaron colgajos submentales tras resección de tumores orofaríngeos agresivos, Chow y coautores $^{16}$ revisaron 10 casos de reconstrucción y vieron que

Tabla 1: Información general de los casos atendidos.

\begin{tabular}{|c|c|c|c|c|c|c|}
\hline Caso & $\begin{array}{l}\text { Edad } \\
\text { (años) }\end{array}$ & Sexo & Diagnóstico & Procedimiento & $\begin{array}{c}\text { Ingreso } \\
\text { (días) }\end{array}$ & Complicaciones \\
\hline 1 & 56 & Masculino & CCE en lengua & $H G+D C S O+C S$ & 5 & Ninguna \\
\hline 2 & 82 & Femenino & CCE en lengua & $H G+D C S O+C S$ & 3 & Ninguna \\
\hline 3 & 79 & Femenino & CCE en lengua & $\mathrm{HG}+\mathrm{DCSO}+\mathrm{CS}$ & 4 & Ninguna \\
\hline 4 & 80 & Femenino & Carcinoma mucinoso en carrillo & $\mathrm{RA}+\mathrm{CS}$ & 5 & Congestión venosa \\
\hline 5 & 63 & Femenino & CCE en lengua & $\mathrm{HG}+\mathrm{DCSO}+\mathrm{CS}$ & 4 & Ninguna \\
\hline 6 & 75 & Femenino & CCE en lengua & $\mathrm{HG}+\mathrm{DCSO}+\mathrm{CS}$ & 4 & Ninguna \\
\hline 7 & 52 & Femenino & CCE en lengua & $H G+D C S O+C S$ & 4 & Ninguna \\
\hline 8 & 62 & Femenino & CCE en trígono & $\mathrm{HG}+\mathrm{DCSO}+\mathrm{MS}+\mathrm{CS}$ & 4 & Ninguna \\
\hline 9 & 57 & Masculino & CCE en reborde alveolar inferior & $\mathrm{HG}+\mathrm{DCSO}+\mathrm{MM}+\mathrm{CS}$ & 3 & Ninguna \\
\hline 10 & 71 & Femenino & CCE en lengua & $\mathrm{GP}+\mathrm{DCSO}+\mathrm{CS}$ & 3 & Ninguna \\
\hline 11 & 82 & Femenino & CCE en trígono & $\mathrm{RA}+\mathrm{DCSO}+\mathrm{MS}+\mathrm{CS}$ & 5 & Ninguna \\
\hline 12 & 65 & Femenino & CCE en mucosa del vestíbulo & $\mathrm{HG}+\mathrm{DCSO}+\mathrm{CS}$ & 4 & Necrosis cutánea parcial de un 50\% \\
\hline 13 & 24 & Masculino & CCE en lengua & $\mathrm{HG}+\mathrm{DCSO}+\mathrm{CS}$ & 3 & Ninguna \\
\hline
\end{tabular}

CCE = carcinoma de células escamosas; HM = hemiglosectomía; GP = glosectomía parcial; RA = resección amplia; DCSO = disección de cuello supraomohioidea; $\mathrm{MS}$ = mandibulectomía segmentaria; MP = mandibulectomía parcial; $C S$ = colgajo submental. 
las recurrencias de la enfermedad estaban más relacionadas con la agresividad del tumor primario que con la «transgresión» oncológica que pudiese suponer el realizar este recorte. La reconstrucción con el colgajo de este tipo no aumenta el riesgo de recurrencia locorregional en pacientes con T1-2 con ganglios positivos. ${ }^{17}$

El cirujano ha de estar preparado para experimentar cualquier sorpresa oncológica, como encontrar ganglios linfáticos positivos en el nivel I, que podrían verse intraoperatoriamente o demostrarse mediante cortes congelados. El cirujano no debe dudar en realizar la disección del cuello contralateral en tal situación. Si lo considera necesario, el cirujano precisa abandonar el colgajo y pensar en otra opción reconstructiva.

La mayor parte de la literatura no ha evaluado el efecto de la irradiación sobre la viabilidad del colgajo. Sin embargo, en la experiencia de Taghinia y asociados, la radioterapia preoperatoria fue el hallazgo más consistente en aquellos que sufrieron pérdida del recorte. ${ }^{17,18}$

Otras contraindicaciones para el uso del colgajo submentoniano son la ligadura de la arteria facial y la cirugía de cuello previa. ${ }^{19}$ Se recomienda precaución al doblar el retazo en el cuello obeso. Según esta experiencia, la necesidad de radioterapia postoperatoria no es una contraindicación.

Otra desventaja es que el recorte puede llevar pelos, en algunas instancias esta característica podría ser útilmente empleada, por ejemplo, en la reconstrucción de los portadores de pelo en el labio superior. Este problema se ha manejado utilizando diferentes técnicas, como la ablación con láser, segundas operaciones, depilación mecánica y electrólisis. ${ }^{20,21}$ Una variante es desepitelizar el colgajo submental, esta modalidad se introdujo para resolver ese problema en reconstrucción intraoral, orofaríngea y laríngea en pacientes de sexo masculino. ${ }^{22,23}$

Hay una amplia variedad de colgajos para la reconstrucción de la cara o intraoral, pero se cree que el retazo en isla submentoniano es una importante adición en el ya existente arsenal quirúrgico. A diferencia de la mayoría de los otros recortes locales, ésta deja bien escondido el sitio donante. También se reduce el tiempo operatorio y la hospitalización, sin comprometer los resultados funcionales.

\section{Conclusión}

Es un colgajo ideal para la reconstrucción de tejidos blandos de cabeza y cuello por su delgadez, flexibilidad y versatilidad en el diseño. También presenta una excelente combinación de colores para la región de la cabeza y el cuello y se puede levantar fácilmente. Su uso no debe comprometer la seguridad oncológica del procedimiento.

Llega a ser una excelente opción en enfermos con reserva fisiológica limitada, en quienes el trauma operatorio y la recuperación postoperatoria tardía son los problemas más complicados. Además, en pacientes de edad avanzada, este colgajo evita las complicaciones potenciales vinculadas a procedimientos microquirúrgicos.

\section{Referencias}

1. Mazzola RF, Oldini C, Sambataro G. Use of submandibular flap to close pharyngostomes and other defects of lower anterior neck region. Plast Reconstr Surg. 1979; 64 (3): 340-346.

2. Calabrese L, Accorona R, Gazzini L, Giorgetti G, Tagliabue M, Bruschini R, et al. Platysma myocutaneous flap revised in the free flaps era: clinical experience in 61 patients. Acta Otorhinolaryngol Ital. 2020; 40 (3): 173-180. doi: 10.14639/0392-100X-N0538.

3. Padiyar BV, Azeem Mohiyuddin SM, Sagayaraj A, Merchant S. Usefulness of supraclavicular flap in reconstruction following resection of oral cancer. World J Otorhinolaryngol Head Neck Surg. 2017; 4 (2): 148-152.

4. Jorgensen MG, Tabatabaeifar S, Toyserkani NM, Sorensen JA. Submental island flap versus free flap reconstruction for complex head and neck defects. Otolaryngol Head Neck Surg. 2019; 161 (6): 946-953.

5. Gray ML, Drake VE, Desai SC. Resurgence of regional flaps for head and neck reconstruction. Curr Opin Otolaryngol Head Neck Surg. 2021; 29 (4): 237-243.

6. Martin D, Pascal JF, Baudet J, Mondie JM, Farhat JB, Athoum A, et al. The submental island flap: a new donor site. Anatomy and clinical applications as a free or pedicled flap. Plast Reconstr Surg. 1993; 92 (5): 867-873.

7. Sterne GD, Januszkiewicz JS, Hall PN, Bardsley AF. The submental island flap. Br J Plast Surg. 1996; 49 (2): 85-89.

8. Faltaous AA, Yetman RJ. The submental artery flap: an anatomic study. Plast Reconstr Surg. 1996; 97 (1): 56-60; discussion 61-62.

9. Whetzel TP, Mathes SJ. Arterial anatomy of the face: an analysis of vascular territories and perforating cutaneous vessels. Plast Reconstr Surg. 1992; 89 (4): 591-603; discussion 604-605.

10. Amin AA, Sakkary MA, Khalil AA, Rifaat MA, Zayed SB. The submental flap for oral cavity reconstruction: extended indications and technical refinements. Head Neck Oncol. 2011; 3: 51.

11. Patel UA, Bayles SW, Hayden RE. The submental flap: a modified technique for resident training. Laryngoscope. 2007; 117 (1): 186-189.

12. Sebastian $P$, Thomas $S$, Varghese BT, lype EM, Balagopal PG, Mathew PC. El colgajo en isla submentoniano para la reconstrucción de defectos intraorales en pacientes con cáncer oral. Oral Oncol. 2008; 44 (11): 1014-1018.

13. Faisal M, Adeel M, Riaz S, Anwar A, Rashid A, Usman S, et al. The Submental island flap in head and neck cancer. Ann Maxillofac Surg. 2018; 8 (2): 287-291. doi: 10.4103/ams.ams_225_18.

14. Yamauchi M, Yotsuyanagi T, Ezoe K, Saito T, Ikeda K, Arai K. Reverse facial artery flap from the submental region. J Plast Reconstr Aesthet Surg. 2010; 63 (4): 583-588.

15. Wang J, Tan Y, Shen Y, Lv M, Li J, Sun J. Oncological safety of submental island flap for reconstruction of pathologically node-negative and node-positive T1-2 oral squamous cell carcinoma-related defects: A retrospective study and comparison of outcomes. Oral Oncol. 2020; 102: 104507.

16. Chow TL, Chan TT, Chow TK, Fung SC, Lam SH. Reconstruction with submental flap for aggressive orofacial cancer. Plast Reconstr Surg. 2007; 120 (2): 431-436.

17. Taghinia AH, Movassaghi K, Wang AX, Pribaz JJ. Reconstruction of the upper aerodigestive tract with the submental artery flap. Plast Reconstr Surg. 2009; 123 (2): 562-570. 
18. Paydarfar JA, Patel UA. Submental island pedicled flap vs radial forearm free flap for oral reconstruction: comparison of outcomes. Arch Otolaryngol Head Neck Surg. 2011; 137 (1): 82-87.

19. Jiang B, Gu Y, Chen W. Submental island flaps for reconstruction of hypopharyngeal non-circumferential defects after hypopharyngeal carcinoma removal. Zhongguo Xiu Fu Chong Jian Wai Ke Za Zhi. 2006; 20 (12): 1183-1185.

20. Conroy FJ, Mahaffey PJ. Intraoral flap depilation using the longpulsed alexandrite laser. J Plast Reconstr Aesthet Surg. 2009; 62 (11): e421-e423.

21. Hall RR, Pearce DJ, Brown T, McMichael AJ. Unwanted palatal hair: a consequence of complex oropharyngeal reconstruction. J Dermatolog Treat. 2009; 20 (3): 149-151.
22. Vural E, Suen JY. The submental island flap in head and neck reconstruction. Head Neck. 2000; 22 (6): 572-578.

23. Lee JC, Chu YH, Lin YS, Kao CH. Reconstruction of hypopharyngeal defects with submental flap after laryngopharyngectomy. Eur Arch Otorhinolaryngol. 2013; 270 (1): 319-323.

Correspondencia:

Dr. Zoilo Núñez Gil

E-mail: zoilomaxilofacial@gmail.com 